\title{
Combined Solvent Extraction-Graphite Furnace Atomic Absorption Spectrometry for the Determination of Antimony in Plant Materials
}

\author{
Toshio Suzuki, Hiroyuki OzakI and Kiyoshi Sawada \\ Department of Chemistry, Faculty of Science, Niigata University, Ikarashi Ninocho, Niigata 950-21
}

\begin{abstract}
A method based on solvent extraction with capriquat(trioctyl methylammonium chloride) and subsequent graphite furnace atomic absorption spectrometry of antimony has been described. Antimony (III) and antimony (V) are quantitatively extracted with $1 \%(\mathrm{w} / \mathrm{v})$ capriquat in xylene from $0.1 \mathrm{M}$ potassium iodide and $0.5 \mathrm{M}$ sulfuric acid solution. The presence of chloride, sulfate, nitrate and perchlorate ions does not interfere with the extraction of antimony. A 20 $\mu l$ aliquot of the organic phase containing antimony was injected into the carbon tube in the graphite furnace atomizer and the optimum conditions of ashing and atomizing were studied. The addition of copper(II) ion and ascorbic acid gave an excellent lineality for the calibration curve and better sensitivity for the determination of antimony. The present method has been applied to the determination of antimony in NBS SRM 1571, Orchard Leaves. The result obtained agreed well with the certified value.
\end{abstract}

Keywords Extraction, graphite furnace atomic absorption spectrometry, antimony, capriquat, plant

Currently available methods of separation of trace of antimony in environmental samples in combination with graphite furnace atomic absorption spectrometry involve the solvent extraction ${ }^{1-3}$ and manganese dioxide coprecipitation. ${ }^{4}$ The hydride separation of antimony has also been used. ${ }^{5}$ The extractions of antimony with methyl isobutyl ketone ${ }^{1,2}$, tributyl phosphate ${ }^{2}$, diethyldithiocarbamate ${ }^{2,3}$, ammonium pyrrolidinethiocarbamate and dithizone ${ }^{3}$ are not specific and tended to extract metal ions, which interfered with graphite furnace atomic absorption spectrometry. On the other hand, the use of manganese dioxide coprecipitation required a long time for the procedure of coprecipitation. In this paper, capriquat (trioctyl methylammonium chloride) was adopted as extracting agent for the separation of antimony. The extraction of metal-halide complexes with capriquat has been extensively investigated..$^{6-8}$ However, the extraction of antimony iodide complexes with capriquat has not been reported yet. Therefore, the extraction of antimony(III) and antimony(V) from potassium iodidesulfuric acid solution with capriquat in xylene and the graphite furnace atomic absorption spectrometry of antimony in the organic phase have been investigated.

\section{Experimental}

\section{Reagent}

Standard antimony solution: The standard solution ( $1 \mathrm{mg} \mathrm{ml}^{-1}$ ) of antimony was prepared by dissolving 0.5 $\mathrm{g}$ of antimony metal $(99.999 \%)$ in $25 \mathrm{ml}$ of sulfuric acid and diluting it to $500 \mathrm{ml}$ with sulfuric acid $(1+6) .{ }^{9}$ The stock solution of antimony(III) was prepared by dissolving $0.937 \mathrm{~g}$ antimony trichloride in $500 \mathrm{ml}$ of 3 $M$ hydrochloric acid. Similarly, the stock solution of antimony $(\mathrm{V})$ was prepared by dissolving $1.228 \mathrm{~g}$ antimony pentachloride in $500 \mathrm{ml}$ of $3 \mathrm{M}$ hydrochloric acid. The stock solutions of antimony(III) and antimony(V) were standardized by an atomic absorption spectrometry using antimony standard solution and were diluted as required for working solutions.

Capriquat solution: Capriquat solution $(1 \% \mathrm{~W} / \mathrm{V})$ was prepared by dissolving capriquat (Dojindo Laboratories) in xylene. The solution of chloride salt was converted into iodide or by shaking with an equal volume of $1 \mathrm{M}$ potassium iodide solution for $10 \mathrm{~min}$ befor use.

All the other reagents used were of analytical reagent grade.

\section{Apparatus}

Atomic absorption measurements were made on a 
Shimazu Model 640-01 atomic absorption spectrometer, equipped with a Model GFA-2 graphite furnace atomizer. A Hamamatsu TV antimony hollow-cathode lamp was adopted as a light source. An Iwaki Model KM shaking apparatus was employed for solvent extraction, while a Kubota Model KN-70 centrifuge was used for centrifugation.

\section{Determination of percent extraction of antimony}

An aqueous solution containing antimony(III) or antimony $(\mathrm{V})$, potassium iodide and sulfuric acid was shaken with a capriquat solution in a stoppered centrifuging tube at room temperature for $5 \mathrm{~min}$. After centrifugation at $3000 \mathrm{~min}^{-1}$ for $5 \mathrm{~min}$, the phases were separated and the antimony in the aqueous phase was determined by flame or graphite furnace atomic absorption spectrometry. On the other hand, antimony in the organic phase was back-extracted into ethylenediamine solution, and was determined as before. The extraction percent of antimony was calculated from antimony contents of both phases.

\section{Determination of antimony in the standard reference material}

Dry the sample in oven at $85^{\circ} \mathrm{C}$ for at least $4 \mathrm{~h}$. Weigh out $1 \mathrm{~g}$ of sample into a quartz beaker, add $5 \mathrm{ml}$ of nitric acid or hydrogen peroxide and $3 \mathrm{ml}$ of sulfuric acid, and heat the sample on a hot plate until the fumes of sulfuric acid rise. Repeat this procedure to allow the sample solution to become almost colorless and clear. Dissolve the residue with $0.5 \mathrm{M}$ sulfuric acid, filter, and dilute to $50 \mathrm{ml}$ with $0.5 \mathrm{M}$ sulfuric acid. Transfer $10 \mathrm{ml}$ of the sample solution to a stoppered centrifuging tube. Add $2 \mathrm{ml}$ of $9.75 \%(\mathrm{w} / \mathrm{v})$ ascorbic acid- $0.5 \mathrm{M}$ sulfuric acid solution, $1 \mathrm{ml}$ of $1.3 \mathrm{M}$ potassium iodide- $0.5 \mathrm{M}$ sulfuric acid solution, and $50 \mu \mathrm{l}$ of $1 \mathrm{mg} \mathrm{ml} l^{-1}$ copper(II)-0.5 M sulfuric acid solution, and mix well. Add a $4 \mathrm{ml}$ amount of $1 \%(\mathrm{w} / \mathrm{v})$ capriquat solution, shake for $5 \mathrm{~min}$, and centrifuge. Determine the antimony concentration in the organic phase by atomic absorption spectrometry.

\section{Results and Discussion}

Extraction of antimony from potassium iodide-sulfuric acid solutions.

With use of $1 \%(\mathrm{w} / \mathrm{v})$ capriquat solution in xylene, antimony(III) and antimony(V) were extracted from potassium iodide solution containing $0.5 \mathrm{M}$ sulfuric acid. Each antimony was extracted completely in the range of potassium iodide concentration 0.05 to $0.2 \mathrm{M}$, as shown in Fig. 1. On the basis of this result, subsequent extraction was carried out in a $0.1 \mathrm{M}$ of potassium iodide concentration. The percent extractions of antimony(III) and antimony(V) into xylene without capriquat from the same extracting solution were only $21.4 \%$ and $16.3 \%$, respectively. Effects of capriquat, sulfuric acid concentration and shaking time

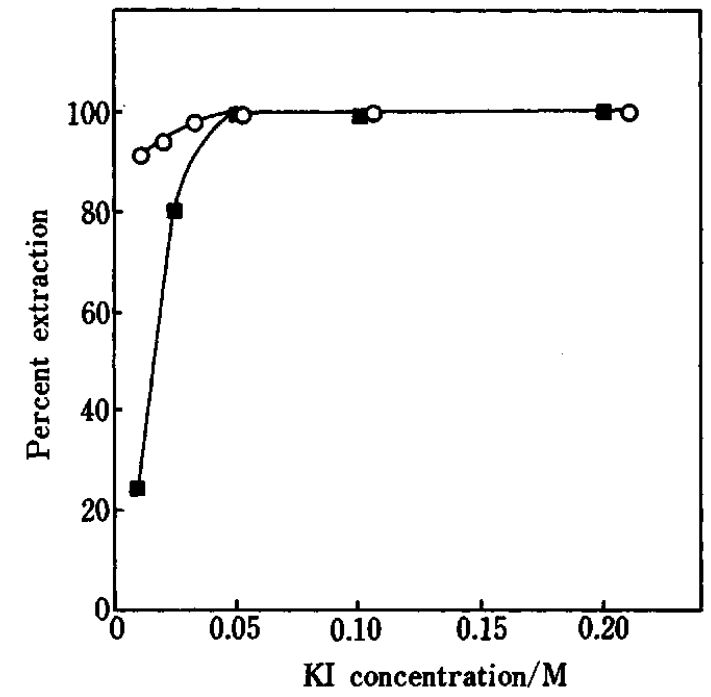

Fig. 1 Effect of KI concentration on the extraction of $\mathrm{Sb}(\mathrm{III})$ and $\mathrm{Sb}(\mathrm{V})$ from $\mathrm{KI}-\mathrm{H}_{2} \mathrm{SO}_{4}$ solution by $1 \%(\mathrm{w} / \mathrm{v})$ capriquat, $\mathrm{O}, \mathrm{Sb}(\mathrm{III}) ; \mathrm{I}, \mathrm{Sb}(\mathrm{V}) . \mathrm{H}_{2} \mathrm{SO}_{4}, 0.5 \mathrm{M} ; \mathrm{Sb}, 10 \mu \mathrm{g}$ $\mathrm{ml}^{-1}$.

Table 1 Percent extraction of $\mathrm{Sb}(\mathrm{III})$ and $\mathrm{Sb}(\mathrm{V})$

\begin{tabular}{ccc}
\hline \multirow{3}{*}{$\begin{array}{c}\text { (1) Effect of capriquat concentration } \\
\text { Capriquat concentration, } \\
\%(w / v)\end{array}$} & \multicolumn{2}{c}{ Extraction, $\%$} \\
\cline { 2 - 3 } & $\mathrm{Sb}(\mathrm{III})$ & $\mathrm{Sb}(\mathrm{V})$ \\
\hline 0.1 & 100 & 99.6 \\
0.5 & 100 & 100 \\
1.0 & 100 & 100 \\
3.0 & 100 & 100 \\
5.0 & 100 & 100 \\
\hline
\end{tabular}

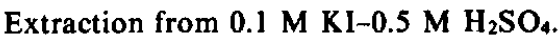

\begin{tabular}{ccc}
\hline \multicolumn{3}{c}{$\begin{array}{c}\text { (2) Effect of } \mathrm{H}_{2} \mathrm{SO}_{4} \text { concentration } \\
\mathrm{H}_{2} \mathrm{SO}_{4} /\end{array}$} \\
\cline { 2 - 3 } & $\mathrm{Sb}(\mathrm{III})$ & $\mathrm{Sb}(\mathrm{V})$ \\
\hline 0.25 & 98.8 & 98.9 \\
0.5 & 100 & 100 \\
1.5 & 100 & 100 \\
3.0 & 100 & 100 \\
\hline
\end{tabular}

Extraction from $0.1 \mathrm{M} \mathrm{KI}$ with $1 \%$ capriquat.

Table 2 Back-extraction of $\mathrm{Sb}(\mathrm{III})$ and $\mathrm{Sb}(\mathrm{V})$

\begin{tabular}{cccc}
\hline \multirow{2}{*}{ Stripping agent } & Concentration & \multicolumn{2}{c}{ Back-extraction, \% } \\
\cline { 3 - 4 } & & $\mathrm{Sb}(\mathrm{HII})$ & $\mathrm{Sb}(\mathrm{V})$ \\
\hline $\mathrm{HClO}_{4}$ & $0.5 \mathrm{M}$ & 66.6 & \\
$\mathrm{HNO}_{3}$ & $1.0 \mathrm{M}$ & 2.2 & \\
$\mathrm{NaOH}$ & $0.5 \mathrm{M}$ & 99.1 & 97.7 \\
$\begin{array}{c}\text { Triethylene } \\
\text { tetramine }\end{array}$ & $10 \%$ & 98.6 & \\
Ethylenedi- & $1.0 \%$ & 100 & 100 \\
amine & $5.0 \%$ & 100 & 100 \\
\hline
\end{tabular}

Extraction from $0.1 \mathrm{M} \mathrm{KI}-0.5 \mathrm{M} \mathrm{H}_{2} \mathrm{SO}_{4}$ with $1 \%$ capriquat. 
on the extraction of antimony were investigated. It was found that extraction equilibrium of antimony was achieved within $2 \mathrm{~min}$. From Table 1, subsequent extraction of antimony was carried out from $0.1 \mathrm{M}$ potassium iodide- $0.5 \mathrm{M}$ sulfuric acid solution with $1 \%$ (w/v) capriquat solution in xylene by shaking for 5 min. Antimony(III) and antimony(V) were further found to be quantitatively extracted under the same extraction condition even if the volume ratio of the aqueous to organic phase was 10:1.

Several stripping agents, such as acid, alkali and ethylenediamine, were tested in order to back-extract the antimony in the organic phase. As shown in Table 2 , antimony(III) and antimony(V) were quantitatively back-extracted into ethylene-diamine solution.

\section{Effects of various anions on the extraction of antimony}

Effects of various anions on the extraction of antimony(III) and antimony(V) from the potassium iodide-sulfuric acid medium were examined. As shown in Table 3, the presence of chloride, sulfate, nitrate and perchlorate ions did not interfere with the extraction of antimony to any great extent. However, tartrate interfered with the extraction of antimony greatly. This effects come from the fact that antimony forms

Table 3 Effect of anions on extraction of $\mathrm{Sb}(\mathrm{III}, \mathrm{V})$

\begin{tabular}{|c|c|c|c|c|}
\hline \multirow{2}{*}{ Anions } & \multirow{2}{*}{ Added as } & \multirow{2}{*}{ Concn./M } & \multicolumn{2}{|c|}{ Extraction, \% } \\
\hline & & & $\mathrm{Sb}(\mathrm{III})$ & $\mathrm{Sb}(\mathrm{V})$ \\
\hline \multirow[t]{4}{*}{$\mathrm{Cl}^{-}$} & $\mathrm{Na}$ salt & 0.1 & 100 & 100 \\
\hline & & 0.5 & 100 & 100 \\
\hline & & 1.0 & 100 & 100 \\
\hline & & 1.5 & 100 & 100 \\
\hline \multirow[t]{4}{*}{$\mathrm{SO}_{4}{ }^{2-}$} & Na salt & 0.1 & 100 & 100 \\
\hline & & 0.5 & 100 & 100 \\
\hline & & 1.0 & 97.6 & 97.9 \\
\hline & & 1.5 & 97.3 & 91.8 \\
\hline \multirow[t]{4}{*}{$\mathrm{NO}_{3}^{-}$} & $\mathrm{Na}$ salt & 0.1 & 100 & 100 \\
\hline & & 0.5 & 100 & 100 \\
\hline & & 1.0 & 100 & 100 \\
\hline & & 1.5 & 100 & 100 \\
\hline \multirow[t]{4}{*}{$\mathrm{ClO}_{4}^{-\mathrm{a}}$} & $\mathrm{NH}_{4}{ }^{+}$salt & 0.1 & 99.6 & 99.2 \\
\hline & & 0.25 & 99.6 & 99.0 \\
\hline & & 0.5 & 98.3 & 98.4 \\
\hline & & 1.0 & 99.0 & 98.4 \\
\hline \multirow[t]{4}{*}{$\mathrm{C}_{4} \mathrm{H}_{4} \mathrm{O}_{6}{ }^{2-}$} & Tartaric & 0.1 & 75.4 & 52.9 \\
\hline & acid & 0.2 & 74.7 & 44.3 \\
\hline & & 0.3 & 77.3 & 41.9 \\
\hline & & 0.5 & 82.6 & 37.8 \\
\hline \multirow[t]{6}{*}{$\mathrm{C}_{6} \mathrm{H}_{7} \mathrm{O}_{6}^{-}$} & Ascorbic & $0.1 \%$ & 100 & 100 \\
\hline & acid & $0.3 \%$ & 100 & 100 \\
\hline & & $0.5 \%$ & 100 & 100 \\
\hline & & $1.0 \%$ & 100 & 100 \\
\hline & & $2.0 \%$ & 100 & 100 \\
\hline & & $3.0 \%$ & 100 & 100 \\
\hline
\end{tabular}

Extraction from $0.1 \mathrm{M} \mathrm{KI}-0.5 \mathrm{M} \mathrm{H}_{2} \mathrm{SO}_{4}$ solution with $1 \%$ capriquat.

a. Substituted NaI for KI. the complex with tartrate. Ascorbic acid did not influence the extraction of antimony. An addition of ascorbic acid serves to prevent oxidation of iodide ion and also eliminates the extraction of iron(III) under the proposed extraction.

Graphite furnace atomic absorption spectrometry of antimony in the organic phase

In order to determine the optimim condition of ashing and atomizing, a $20 \mu \mathrm{l}$ of the organic phase containing antimony was injected by means of a micropipet into the graphite tube in the atomizer. Argon was used as the inert gas and the flow rate was maintained at $1.51 \mathrm{~min}^{-1}$. Drying condition was set at $15 \mathrm{~A}\left(\mathrm{ca} .200^{\circ} \mathrm{C}\right)$ for $60 \mathrm{~s}$. As a result, the capriquat solution was completely decomposed without loss of antimony when ashing at $70 \mathrm{~A}\left(\mathrm{ca} .1150^{\circ} \mathrm{C}\right)$ for $60 \mathrm{~s}$. Atomizing condition of $200 \mathrm{~A}\left(\mathrm{ca} .2500^{\circ} \mathrm{C}\right)$ for $8 \mathrm{~s}$ showed a maximum absorbance of antimony. The influence of ascorbic acid, which was added to prevent the oxidation of iodide ion, has been investigated under the above condition. As shown in Fig. 2, the absorbance of antimony was enhanced with increasing concentration of ascorbic acid, and was almost constant at concentrations above $1 \%(\mathrm{w} / \mathrm{v})$ of ascorbic acid. It has already been reported that the addition of ascorbic acid resulted in an increase in sensitivity for the determination of lead ${ }^{10,11}, \operatorname{tin}^{11,12}$ and manganese. ${ }^{11,13}$ On the basis of these results, $1.5 \%(\mathrm{w} / \mathrm{v})$ of ascorbic acid was added in the subsequent extraction.

\section{Effect of diverse ions on the determination of antimony}

For the purpose of applying the present method to the determination of antimony in the standard reference plant material, the interference of various metal ions on the determination of antimony was studied. Antimony of $50 \mathrm{ng} \mathrm{m}^{-1}$ was extracted from the solution containing various metal ions and determined by the above method. The amount of metal ion added was approximately equivalent to that

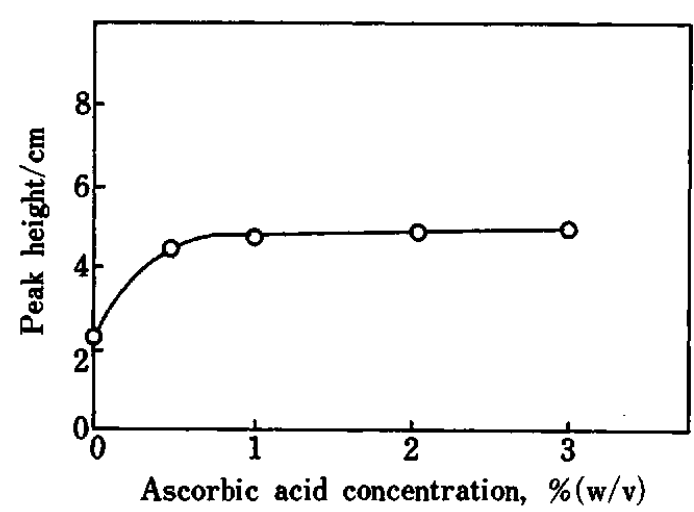

Fig. 2 Effect of ascorbic acid concentration. $\mathrm{Sb}, 600 \mathrm{ng}$; aq. phase: $0.1 \mathrm{M} \mathrm{KI}, 0.5 \mathrm{M} \mathrm{H}_{2} \mathrm{SO}_{4}, 12 \mathrm{ml}$; org. phase: $1 \%(\mathrm{w} / \mathrm{v})$ capriquat $4 \mathrm{ml}$. 


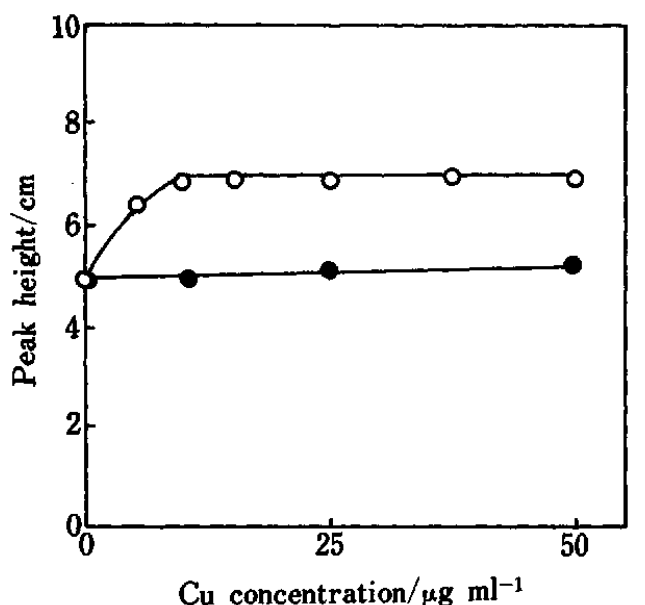

Fig. 3 Effects of $\mathrm{Cu}(\mathrm{II}), \mathrm{Pb}$ concentration in the organic phase. $\mathrm{Sb}, 600 \mathrm{ng}$; aq. phase: $1.5 \%(\mathrm{w} / \mathrm{v})$ ascorbic acid, 0.1 $\mathrm{M} \mathrm{KI}, 0.5 \mathrm{M} \mathrm{H}_{2} \mathrm{SO}_{4}, 12 \mathrm{ml}$; org. phase: $1 \%(\mathrm{w} / \mathrm{v})$ capriquat $4 \mathrm{ml}$. O, $\mathrm{Cu} ;$ O, $\mathrm{Pb}$.

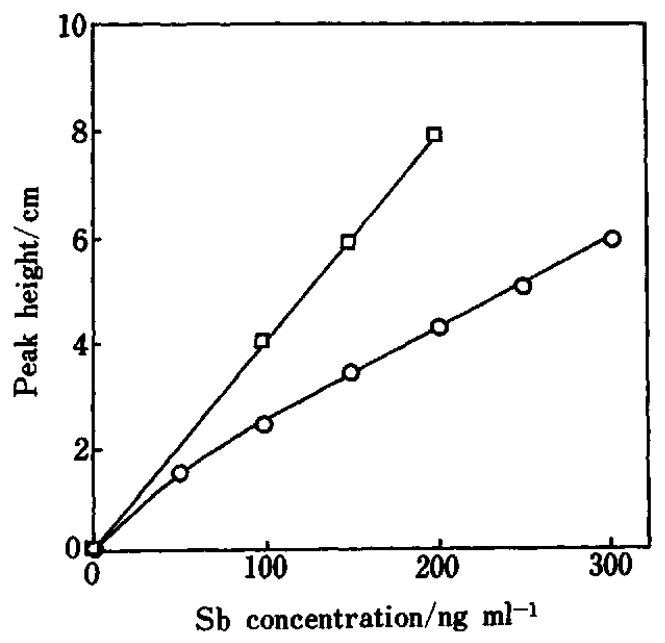

Fig. 4 Calibration curve for $\mathrm{Sb}$ in the organic phase. Aq. phase: $1.5 \%(\mathrm{w} / \mathrm{v})$ ascorbic acid, $0.1 \mathrm{M} \mathrm{KI}, 0.5 \mathrm{M} \mathrm{H}_{2} \mathrm{SO}_{4}$, $12 \mathrm{ml}$; org, phase: $1 \%(\mathrm{w} / \mathrm{v})$ capriquat $4 \mathrm{ml}$. $\square, \mathrm{Cu}$ added; $\mathrm{O}, \mathrm{Cu}$ not added.

of Orchard Leaves. All the metal ions except for copper(II) have almost no influence on the determination of antimony, as shown in Table 4. In this extraction system, copper(II) and lead were quantitatively extracted into organic phase together with antimony. ${ }^{8}$ Therefore, the influence of copper(II) and lead ions was studied in detail. The correlation between the peak of antimony and copper(II) or lead concentration is shown in Fig. 3. The peak hight of antimony was not affected by the concentration of lead extracted, but copper(II) ion showed a significant influence on antimony absorption at the concentration of less than $10 \mu \mathrm{g} \mathrm{ml}^{-1}$. On the other hand, extracted copper(II) of concentrations above $10 \mu \mathrm{g} \mathrm{ml}^{-1}$ had little
Table 4 Effect of diverse cations on the determination of antimony

\begin{tabular}{|c|c|c|c|}
\hline Ions & $\begin{array}{l}\text { Added/ } \\
\mu \mathrm{g} \mathrm{ml}^{-1}\end{array}$ & $\begin{array}{l}\text { Sb found/ } \\
\mathrm{ng} \mathrm{ml}^{-1}\end{array}$ & $\begin{array}{c}\text { Relative error } \\
\%\end{array}$ \\
\hline $\mathrm{Ca}$ & 400 & 50 & 0 \\
\hline K & 300 & 50 & 0 \\
\hline $\mathbf{M g}$ & 100 & 49 & -2 \\
\hline $\mathrm{Fe}(\mathrm{III})$ & 10 & 50 & 0 \\
\hline $\mathrm{Al}$ & 10 & 50 & 0 \\
\hline $\operatorname{Mn}(\mathrm{II})$ & 10 & 50 & 0 \\
\hline $\mathrm{Na}$ & 10 & 49 & -2 \\
\hline $\mathbf{P b}$ & 10 & 49 & -2 \\
\hline $\mathrm{Ba}$ & 10 & 50 & 0 \\
\hline $\mathrm{Sr}$ & 10 & 50 & 0 \\
\hline $\mathrm{Zn}$ & 10 & 51 & +2 \\
\hline $\mathbf{R b}$ & 1 & 50 & 0 \\
\hline As & 1 & 50 & 0 \\
\hline $\mathrm{Cu}$ & 0.2 & 57 & +14 \\
\hline
\end{tabular}

$\mathrm{Sb}$ added, $50 \mathrm{ng} \mathrm{ml}^{-1}$; aq. phase, $1.5 \%(\mathrm{w} / \mathrm{v})$ ascorbic

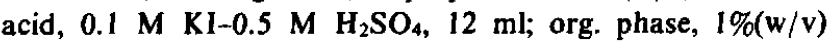
capriquat-xylene, $4 \mathrm{ml}$.

Table 5 Determination of antimony in standard plant materials

\begin{tabular}{|c|c|c|c|c|}
\hline \multirow{2}{*}{ Digestion } & \multicolumn{3}{|c|}{$\mathrm{Sb} / \mu \mathrm{g} \mathrm{g}^{-1}$} & \multirow{2}{*}{ rsd, \% } \\
\hline & Found & $n$ & Certified & \\
\hline \multicolumn{5}{|l|}{ Orchard Leaves ${ }^{a}$} \\
\hline $\mathrm{HNO}_{3}-\mathrm{H}_{2} \mathrm{SO}_{4}$ & $2.8 \pm 0.2$ & 6 & $2.9 \pm 0.3$ & 2.2 \\
\hline $\mathrm{H}_{2} \mathrm{O}_{2}-\mathrm{H}_{2} \mathrm{SO}_{4}$ & $2.7 \pm 0.3$ & 4 & $2.9 \pm 0.3$ & 3.8 \\
\hline \multicolumn{5}{|l|}{ Tea Leaves ${ }^{b}$} \\
\hline $\mathrm{HNO}_{3}-\mathrm{H}_{2} \mathrm{SO}_{4}$ & 0.1 & 4 & & \\
\hline $\mathrm{HNO}_{3}-\mathrm{H}_{2} \mathrm{SO}_{4}$ & $5.1 \pm 0.2^{c}$ & 4 & & 2.6 \\
\hline
\end{tabular}

a. SRM 1571 .

b. The National Institute for Environmental Studies reference material.

c. Obtained by the addition of $5.0 \mu \mathrm{g} \mathrm{Sb} \mathrm{g}^{-1}$.

influence on the peak hight, and resulted in an increase in sensitivity of antimony. On the basis of these observations, copper(II) ion was added in the extraction system of antimony.

\section{Calibration curve}

A typical calibration curve of peak hight $v s$. antimony concentration in organic phase is shown in Fig. 4. The existence of copper(II) in the organic phase has given an excellent lineality and sensitivity, as can be seen from the calibration curve. The sensitivity for $1 \%$ absorption in the organic phase showed $6 \mathrm{ng} \mathrm{ml}^{-1}$ for antimony.

According to the previously outlined procedure, 
antimony in the standard reference material was determined. Analytical results are given in Table 5. All the values obtained by the proposed method agree well with the certified value.

\section{References}

1. M. Morita and M. Mishima, Bunseki Kagaku, 30, 170 (1981).

2. M. Yanagisawa and T. Takeuchi, Anal. Chim. Acta, 64, 381 (1973).

3. T. Kamada and Y. Yamamoto, Talanta, 24, 330 (1977).

4. S. Nakamura, N. Fudagawa and A. Kawase, Bunseki Kagaku, 29, 477 (1980).

5. S. Terashima, Bunseki Kagaku, 23, 1331 (1974).

6. T. Suzuki, H. Kobayashi and K. Sawada, Nippon Kagaku Kaishi, 1982, 1167.
7. T. Suzuki, M. Suwabe, K. Sawada and F. Shirai, Bunseki Kagaku, 32, 757 (1983).

8. T. Suzuki and T. Sotobayashi, Nippon Kagaku Kaishi, 87, 587 (1966).

9. S. Hirano ed., "Inorganic colorimetric analysis No. 4" (in Japanese), p. 462, Kyoritsu Press, Tokyo (1975).

10. J. G. T. Regan and J. Warren, Analyst [London], 101, 220 (1976).

11. M. Tominaga and Y. Umezaki, Anal. Chim. Acta, 139, 279 (1982).

12. M. Tominaga and Y. Umezaki, Anal. Chim. Acta, 110, 55 (1979).

13. M. Tominaga and Y. Umezaki, Nippon Kagaku Kaishi, 1981, 7 .

(Received September 9, 1985)

(Accepted November 9, 1985) 